\author{
Revista Venezolana de Gerencia (RVG) \\ Año 7. № 19, 2002, 351-352 \\ Universidad del Zulia (LUZ) • ISSN 1315-9984
}

\title{
EDITORIAL
}

\section{Avanzamos en la investigación gerencial}

Se culmina próximamente en el mes de octubre del presente año, un período de gestión (1999-2002), en el Centro de Estudios de la Empresa (CEE) de la Facultad de Ciencias Económicas y Sociales de la Universidad del Zulia (LUZ), bajo la dirección de la Prof. Teresa Gamboa Cáceres. En esta gestión se desarrolló una política de crecimiento, reflejada por una parte en la incorporación activa a la investigación de un número significativo de profesores de nuestra facultad y de otras como es el caso de Humanidades, Arquitectura, Ingeniería, Ciencias Jurídicas y Políticas y del Núcleo de Cabimas, así como de otras universidades e instituciones de la región: La Universidad Rafael María Baralt, Fundación Fe y Alegría y la Central de Cooperativas del Estado Zulia. Por otra parte se ha impulsado el ingreso de nuevos investigadores: Becarios Académicos, con recursos externos, seis financiados a través del Programa Investigador Novel (PIN) del Fondo Nacional de Investigaciones Científicas y Tecnológicas (FONACIT) y tres por la Fundación para el Desarrollo Académico Integral de la Universidad del Zulia (FUNDADE. SARROLLO-LUZ), lo que hace un total de nueve jóvenes investigadores en proceso de formación en el campo de la Gerencia, tutoriados por investigadores del CEE acreditados en el Programa de Promoción al Investigador (PPI) del FONACIT y con un proceso previo de formación iniciado en su condición de auxiliar de investigación con financiamiento del CONDES.

Se encuentran en desarrollo 10 líneas de investigación, a través de 41 proyectos, algunos organizados en programas, financiados en su mayoría por el Consejo de Desarrollo Científico y Humanístico (CONDES) de LUZ, los cuales además sirven de soporte a tesis de pregrado y postgrado (especializaciones, maestrías y doctorados). La productividad de este proceso ha permitido pasar de tres a catorce investigadores acreditados en el PPI.

Como parte de esta política de avance en la investigación gerencial, durante estos tres años, el CEE realizó varios encuentros para intercambiar experiencias y resultados de investigación, entre estos eventos se destaca el I Congreso Internacional de Gerencia en América Latina, promovido conjuntamente por el CEE, la División de Estudios para Graduados y la Revista Venezolana de Gerencia, adscrita al CEE.

En este contexto editamos el No. 19 de la Revista Venezolana de Gerencia, donde se publican seis artículos y un ensayo, de investigadores de varia instituciones y países.

En el marco del estudio de las organizaciones empresariales y su evolución para responder a los retos a enfrentar en el futuro, se presenta el trabajo de Derlisiret Rincón y María Gracia Romero, "Tendencias organizacionales de las Empresas". También sobre el futuro de las empresas se incluye el trabajo de Jesús Alberto Andrade, titulado: "Sucesión en la empresa fami- 
liar: su futuro cuando la muerte se acerca", quien constata que las empresas familiares se caracterizan por el estrecho nexo cultural y tradicional con la familia que las dirige. Finalmente sobre las empresas, se incluye el trabajo: "Las pequeñas y medianas empresas (PYMES) en Cumaná(Venezuela): Inflación, gerencia y desarrollo", realizado por Guillermina Ramírez, Lissette Solórzano y Yusmelis Rosillo, quienes identifican la poca percepción de los gerentes ante la influencia de la inflación, baja capacidad empleadora, especialmente en lo referente a los trabajos estables, producción global por debajo de las bandas aceptadas por los organismos de seguimiento, créditos y financiamiento del sector lo que podría ser un reflejo de la recesión económica a nivel de las empresas en Cumaná.

Se incluyen dos trabajos que aportan elementos metodológicos para el desarrollo de la actividad científica en diferentes áreas de la gerencia, en tal sentido, uno es el de Gaudy Bravo, titulado: "La producción científica de una unidad de investigación universitaria. Una propuesta metodológica", que expone indicadores que permiten medir la productividad científica y la construcción de una base de datos requerida para fortalecer el proceso de toma de decisión en entes dedicados a la producción de conocimiento, tomando como caso el Instituto de Investigaciones de la Facultad de Arquitectura y Diseño de la Universidad del Zulia. Como plataforma a la actividad de investigación, Alberto Romero, nos presenta con su trabajo "Las redes de información y su importancia para la investigación científica", el análisis de algunas herramientas utilizadas para el intercambio de información y experiencias en la comunidad científica.

Finalmente se incluyen dos trabajos sobre políticas y gestión de lo social. María Elena Romero e Irene Díaz, en su trabajo titulado "Lo cuantitativo y lo cualitativo en la implementación de programas públicos sociales", exploran las bases teóricas y metodológicas utilizadas para elaborar alternativas en la implementación y evaluación de programas sociales desde una perspectiva integradora. Michel Azcueta, en su ensayo "Gestión pública para erradicar la pobreza: Las soluciones existen", analiza la evolución de la pobreza e inequidad en el mundo, su relación con el modelo de desarrollo impulsado durante la globalización y la evaluación de las respuestas que los gobiernos han intentado para enfrentarla.

Por último damos a conocer dos publicaciones recientes: 1) El libro "Hacia una Economía con Rostro Humano" de Bernardo Kliksberg, reseñado por la Dra. Haydée Ochoa Henríquez y 2) El libro "Interpretando organizaciones..." de Ramsés Fuenmayor, reseñado por el Dr. Jorge Dávila.

Mirtha López Valladares*

* Investigadora del Centro de Estudios de la Empresa. 